\title{
Assessment of relative fertility of males (cockerels and boars) by competitive mating
}

\author{
P. A. Martin* and P. J. Dziuk \\ Department of Animal Science, University of Illinois, Urbana, \\ Illinois 61801, U.S.A.
}

\begin{abstract}
Summary. When hens were inseminated with an equal number of spermatozoa from one of 3 Leghorn (L) and one of 3 Columbian (C) cocks in the 9 possible $L$ and $C$ combinations, a hierarchy of fertility was established based on the proportion of chicks sired by each cock. A similar hierarchy was established for 3 Duroc (D) and 3 Yorkshire (Y) boars by mating gilts in rapid succession to one $\mathrm{D}$ and one $\mathrm{Y}$ boar. A second hierarchy of fertility was established by inseminating hens with $40 \times 10^{6}$ spermatozoa from only one cock or by mating gilts to only one of the boars. The hierarchies for the cocks and boars were essentially the same for each method. Minor discrepancies were observed for males which appeared to be nearly equally fertile when used alone or in combination with another male. After homospermic insemination, the hierarchy of cocks was identical whether the ranking was based on the percentage of eggs fertilized or on hatchability of fertilized eggs. Similarly, the boars ranked highest in fertility by double mating had higher conception rates, higher embryonic survival rates and larger litter sizes when used alone. Heterospermic insemination and double mating appear to be more efficient and sensitive than methods of estimating fertility which depend on homospermic insemination of high or low numbers of spermatozoa, single matings or the examination of various characteristics of semen. The method of heterospermic insemination or double mating offers a simple and effective method of assessing the relative fertility of males.
\end{abstract}

\section{Introduction}

Males differ in their fertility. A higher proportion of females conceive after insemination to certain males than after insemination to other males and the number of offspring per litter is also higher from some sires than others (Bishop, 1964; Finn, 1964; Boender, 1966). Because high fertility in domestic animals is essential for the efficient and profitable production of livestock, many attempts have been made to correlate characteristics of the male, his semen, and his spermatozoa, to his fertility. Estimates of fertility based on these relationships are often not accurate and can even be misleading if the correlation is low. Even estimates of fertility based on conception rates and litter size from inseminating a large number of females to one male are uncertain because of the influence of season, competence of the inseminator, nutrition, management, fertility of the female, and other variables. In cattle, competitive mating by heterospermic insemination essentially eliminates these uncertainties and is more than $\mathbf{1 7 0}$ times more sensitive as a means of estimating relative fertility than estimates made by mating to one male as in homospermic inseminations (Beatty, Bennett, Hill, Hancock \& Stewart, 1969). This greater sensitivity would also be useful for the evaluation of males of other species. The following study was conducted to determine the relationship between estimates of fertility obtained by competitive mating and estimates obtained by homospermic inseminations in chickens and pigs.

* Present address: Department of Animal Science, Macdonald College of McGill University, Ste. Anne de Bellevue, Quebec, Canada HOA ICO. 
Materials and Methods

\section{Chickens}

The management of the chickens and the processing and handling of the eggs and semen followed conventional practices as described previously (Martin, Reimers, Lodge \& Dziuk, 1974). Fertility was estimated heterospermically in three Columbian cocks $(\mathrm{C} 1, \mathrm{C} 2, \mathrm{C} 3)$ and in three Leghorn cocks (L0, L1, L2) by inseminating heterospermically in all possible $\mathrm{C}$ and $\mathrm{L}$ combinations and homospermically. For each of the nine possible $C$ and $L$ pairs, the $C$ and $L$ cocks each contributed $50 \times 10^{6}$ spermatozoa to each inseminate. There were 3 or 4 replicates of each $C$ and $L$ pair, except for pairs involving $\mathrm{C} 3$ male. The proportion of offspring from each sire was noted at the time of hatching.

In a second experiment, the relative fertility of the 6 cocks was estimated by homospermic insemination. Semen was collected from each male. Each hen was inseminated with $40 \times 10^{6}$ spermatozoa from one cock. The proportion of eggs fertilized, as determined by candling on Day 7 of incubation, and the percentage hatchability were recorded.

In a third experiment, the influence of the number of spermatozoa on relative homospermic fertility was determined. Four ejaculates were obtained from Cocks $\mathrm{Cl}$ and L1. The semen was extended so that $0.1 \mathrm{ml}$ extended semen contained $100 \times 10^{6}, 50 \times 10^{6}, 25 \times 10^{6}, 12.5 \times 10^{6}, 6.25 \times$ $10^{6}$ or $3.125 \times 10^{6}$ spermatozoa. Three hens were inseminated with each sperm number from each semen sample thus giving 24 hens inseminated with each sperm number. Fertility was determined by candling the eggs on Day 7 of incubation.

\section{Pigs}

The relative fertility of three Duroc boars (D2, D4, D8) and three Yorkshire boars (Y1, Y2, Y4) was estimated following double mating and single mating. The boars were nearly the same age, were handled and managed similarly, and Y1 and Y4 were litter mates. Boars were not selected on any assessment of conformation or fertility. Superficial gross and microscopic examination of the semen revealed no differences between boars. To test for competitive fertility, Duroc gilts, homozygous for red colour, were mated on the first day of oestrus to one of the $D$ boars and to one of the $Y$ boars. The two successive matings were within $10 \mathrm{~min}$ of each other. Fifty-one litters were produced from these matings. For each of the nine possible $\mathrm{D}$ and $\mathrm{Y}$ combinations, the assignment of which boar was mated first was made so that each boar was used first an equal number of times. The sire of each piglet was determined at slaughter after Day 90 or at parturition, when skin colour was distinguishable. The red colour of the Duroc is recessive to the white of the Yorkshire so the skin colour of the piglet corresponded to that of the sire.

To test for fertility from homospermic matings, 5 of the boars used in the competitive mating test were mated singly to crossbred gilts on the first day of oestrus. Boar D2 was unable to mate more than a few gilts, and was excluded. Gilts returning to heat were remated once and if they did not then conceive they were discarded on the assumption that fertility was impaired. The boars were used for mating in a regular rotation as gilts came into oestrus so a boar could, by chance, be remated to a particular gilt at the next heat. The reproductive tracts of the pregnant gilts were examined at Days 3040 of gestation when the number of corpora lutea and fetuses was recorded.

\section{Results}

\section{Chickens}

A total of 1694 chicks were observed in the first experiment using an equal number of spermatozoa from each cock (Table 1). Each of the three $\mathrm{L}$ cocks sired a preponderance of the offspring in all combinations with $\mathrm{C}$ cocks. However, Cock $\mathrm{Cl}$ sired nearly half of the offspring when competing against Cocks L1 or L2. As a consequence of these observations, a ranking of fertility was determined for the 6 cocks according to the following procedure. In the top row of Table 1, Cock C1 can be compared to Cocks L0, L1 and L2. The cock siring the greatest proportion of chicks was assigned 
Table 1. Relative fertility (as \% of chicks sired by $L$ cocks) of 6 cocks after heterospermic insemination

\begin{tabular}{llll}
\hline & Cock L0 & Cock L1 & Cock L2 \\
\hline Cock C1 & $87(198)$ & $59(172)$ & $59(135)$ \\
Cock C2 & $96(284)$ & $96(344)$ & $88(225)$ \\
Cock C3 & $98(67)$ & $99(203)$ & $100(63)$ \\
\hline
\end{tabular}

Each hen received an equal number of spermatozoa from the Leghorn (L) and Columbian (C) cocks. The total number of chicks observed for each $C$ and $L$ pair is shown in parentheses.

number 1 , the cock with the second greatest proportion number 2 , and so on until each of the 4 cocks in that row were assigned a rank number. This was repeated for each row and for each column. The ranking numbers for each male were then added and the total represented his ranking with the low number the highest fertility. On that basis the rank was as follows: $\mathrm{LO}>\mathrm{L} 1>\mathrm{L} 2>\mathrm{Cl}>\mathrm{C} 2>\mathrm{C} 3$.

In the second experiment in which hens were inseminated with $40 \times 10^{6}$ spermatozoa from only one of the 6 cocks, 1163 eggs were examined (Table 2). A ranking of cocks on the basis of the proportion of hens laying fertilized eggs was as follows: $\mathrm{LO}=\mathrm{C} 1=\mathrm{L} 1>\mathrm{L} 2>\mathrm{C} 2>\mathrm{C} 3$. A ranking of the cocks on the basis of the proportion of total eggs from inseminated hens that were fertilized and on the proportion of fertilized eggs that hatched was: $\mathrm{LO}>\mathrm{C} 1>\mathrm{L} 1>\mathrm{L} 2>\mathrm{C} 2>\mathrm{C} 3$. These rankings are in agreement with the ranking of cocks following heterospermic insemination except for Cock C1. Microscopic examination of semen from the 6 cocks indicated that there were no obvious differences between cocks except that a high proportion of spermatozoa from Cock C3 had cytoplasmic droplets.

Table 2. Relative fertility of 6 cocks after homospermic insemination*

\begin{tabular}{lcccccc}
\hline & \multicolumn{2}{c}{ Hens } & & \multicolumn{3}{c}{ Eggs } \\
\cline { 2 - 3 } \cline { 5 - 6 } Cock & No. inseminated & $\%$ Fertile & & Total & $\%$ Fertile & $\%$ Hatched \\
& & & & & & \\
\hline L0 & 30 & 97 & 216 & 80 & 98 \\
L1 & 32 & 97 & 218 & 61 & 92 \\
L2 & 16 & 97 & 101 & 54 & 91 \\
C1 & 29 & 83 & 213 & 64 & 94 \\
C2 & 30 & 6 & 206 & 35 & 88 \\
C3 & 32 & 209 & 1 & 67 \\
\hline
\end{tabular}

${ }^{*}$ Each hen received $40 \times 10^{6}$ spermatozoa from one cock.

Table 3. Fertility in hens after insemination with different numbers of spermatozoa

\begin{tabular}{|c|c|c|c|c|c|c|}
\hline \multirow{2}{*}{$\begin{array}{l}\text { No. of sperm. } \\
\text { inseminated } \times 10^{6}\end{array}$} & \multicolumn{2}{|c|}{$\begin{array}{l}\% \text { Hens laying } \\
\text { fertile eggs }\end{array}$} & \multicolumn{2}{|c|}{$\%$ Fertile eggs } & \multicolumn{2}{|c|}{$\begin{array}{l}\% \text { Fertile eggs } \\
\text { which hatched }\end{array}$} \\
\hline & Cock L1 & Cock C1 & Cock L1 & Cock Cl & Cock L1 & Cock C1 \\
\hline 100 & 100 & 100 & 82 & 78 & 87 & 92 \\
\hline 50 & 100 & 100 & 78 & 77 & 95 & 98 \\
\hline 25 & 92 & 100 & 50 & 63 & 94 & 96 \\
\hline $12 \cdot 5$ & 100 & 92 & 48 & 51 & 96 & 96 \\
\hline $6 \cdot 25$ & 92 & 92 & 47 & 34 & 94 & 94 \\
\hline $3 \cdot 125$ & 92 & 67 & 28 & 19 & 88 & 90 \\
\hline Total & 96 & 92 & 56 & 54 & 92 & 95 \\
\hline
\end{tabular}

Each of the 12 groups consisted of 12 hens and the number of eggs in each group ranged from 100 to 110. 
In the third experiment with variable numbers of spermatozoa from 2 cocks, 1266 eggs were observed for fertility and hatchability. The number of eggs for each of the numbers of spermatozoa ranged from 200 to 224 (Table 3). The regressions of $\log _{n}$ of the number of spermatozoa on percentage fertility for the $\mathrm{L} 1$ and $\mathrm{Cl}$ cocks are shown in Text-fig. 1; differences between the two regression lines were not significant $(P>0 \cdot 2)$.

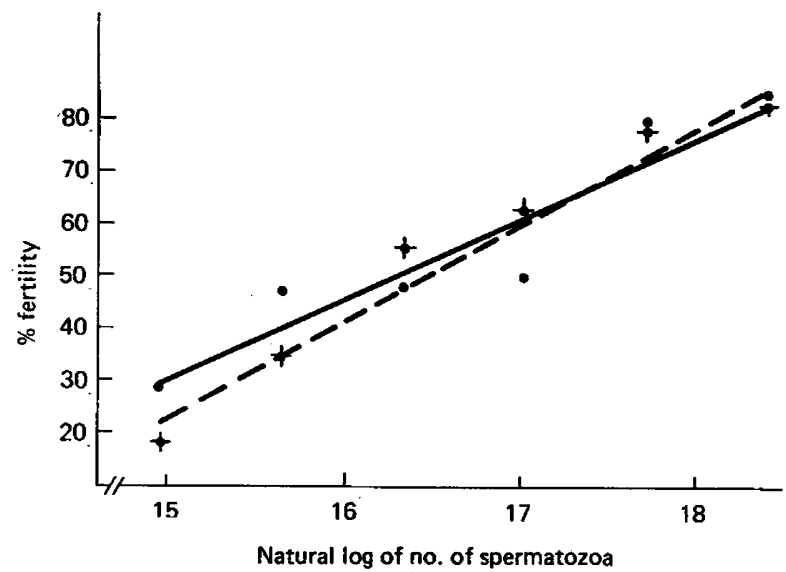

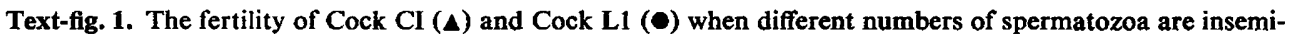
nated. The regressions were $y=-248+18 \operatorname{Ln} x$ for Cock Cl (- - and $y=-197+15 \operatorname{Ln} x$ for Cock L1 ( - $)$.

Table 4. Relative fertility (as \% of piglets sired by $Y$ boars) of 6 boars after double matings

\begin{tabular}{lllr}
\hline & Boar Y1 & Boar Y2 & Boar Y4 \\
\hline Boar D2 & $73(41)$ & $100(7)$ & $6(17)$ \\
Boar D4 & $73(39)$ & $43(75)$ & $29(59)$ \\
Boar D8 & $84(37)$ & $52(45)$ & $17(46)$ \\
\hline
\end{tabular}

The total number of piglets for each pair of Duroc (D) and Yorkshire (Y) boar is given in parentheses.

Table 5. Relative fertility of 5 Duroc (D) and Yorkshire (Y) boars after single matings

\begin{tabular}{cccccccc}
\hline Boar & No. of matings & $\begin{array}{c}\text { No. of matings } \\
\text { to fertile gilts* }\end{array}$ & $\begin{array}{c}\text { No. of gilts } \\
\text { pregnant (\%) }\end{array}$ & No. of CL & $\begin{array}{c}\text { Litter } \\
\text { size }\end{array}$ & $\begin{array}{c}\% \text { Embryonic } \\
\text { survival }\end{array}$ & $\begin{array}{c}\text { Fertility } \\
\text { indext }\end{array}$ \\
\hline Y1 & 34 & 31 & $26(84)$ & $12 \cdot 5$ & $9 \cdot 8$ & 79 & 66 \\
Y2 & 37 & 34 & $30(88)$ & $12 \cdot 6$ & $9 \cdot 4$ & 75 & 66 \\
D4 & 32 & 29 & $24(83)$ & $13 \cdot 3$ & $9 \cdot 4$ & 71 & 59 \\
D8 & 19 & 17 & $13(71)$ & $12 \cdot 1$ & $7 \cdot 6$ & 63 & 44 \\
Y4 & 23 & 15 & $6(40)$ & $13 \cdot 0$ & $7 \cdot 8$ & 60 & 24 \\
\hline
\end{tabular}

* Gilts pregnant after 1 or 2 matings at consecutive oestrous periods.

$\dagger$ Fertility index $=\frac{(\% \text { gilts pregnant }) \times(\% \text { embryonic survival })}{100}$. 
Pigs

The results of the double mating experiment are shown in Table 4. In a total of 51 litters, 24 litters were mixed, 17 litters were sired entirely by the boar first mating the gilt, and 10 litters were sired entirely by the second boar to mate the gilt. The 6 boars were ranked according to their relative fertility as described previously for the chicken. The ranking was $\mathrm{Y} 1>\mathrm{Y} 2=\mathrm{D} 4>\mathrm{D} 2>\mathrm{D} 8>\mathrm{Y} 4$. Boar Y1 sired a greater proportion of offspring than did the D boars in 12 of 14 litters, whereas Boar Y4 sired a greater proportion of offspring than did the D boars in only 3 of 17 litters. The number and percentage of gilts conceiving and the percentage of embryos surviving after mating to individaul boars are shown in Table 5. An index of fertility was determined for each boar by multiplying the $\%$ pregnant gilts $\times \%$ embryonic survival $\times 10^{-2}$. The ranking of boars after this calculation was: $\mathrm{Y} 1=\mathrm{Y} 2>\mathrm{D} 4>\mathrm{D} 8>\mathrm{Y} 4$.

\section{Discussion}

When hens were inseminated with an equal number of spermatozoa from an $\mathrm{L}$ and $\mathrm{C}$ cock or when gilts were mated in rapid succession to $\mathrm{D}$ and $\mathrm{Y}$ boar, one of the males usually sired a preponderance of the offspring. When this procedure was repeated for all possible combinations of $L$ and $C$ cocks (Table 1) and D and Y boars (Table 3), a hierarchy of fertility of males could be established. These observations of a hierarchy are in agreement with those of other workers in the chicken (Allen \& Champion, 1955), rabbit (Beatty, 1960; O'Reilly, Graves \& Dziuk, 1972) and cattle (Beatty et al., 1969; Stewart, Spooner, Bennett, Beatty \& Hancock, 1974). Although different methods were used in the present study for calculating a ranking of males, none changed the rank order.

Males which sired the greatest proportion of offspring following heterospermic insemination or double mating also tended to be more fertile when used alone (Tables 2 and 5). The hierarchies of cocks and boars based on fertility of males following heterospermic insemination or double mating are essentially the same as the hierarchy of males following homospermic insemination or single mating. The minor differences observed in the hierarchies of cocks and boars occurred among males that were about equally fertile. The more fertile cocks, as determined by heterospermic insemination, fertilized a higher proportion of eggs when used alone and a higher proportion of the eggs fertilized by highly fertile cocks hatched when compared to less fertile cocks. Following homospermic insemination, the hierarchies of cocks based on fertility and on hatchability of fertilized eggs were identical (Table 2). Similarly, the more fertile boars following double mating had higher conception rates, higher embryonic survival rates, and larger litter sizes when used alone than did the less fertile boars (Table 5). Because the number of corpora lutea was very similar between groups of gilts, the larger litter sizes for the more fertile boars cannot be attributed to differences in ovulation rates. The nature of the possible differences between boars cannot be determined by this study. Although the differences in litter size and embryonic survival between Boars Y1, Y2 and D4 were small, they are consistent with the ranking established by double mating. The differences between these three boars and Boars D8 and Y4 are greater and are again congruous with the ranking established by double mating.

There have been other studies in pigs of heterospermic insemination by artificial insemination of mixed semen or double mating but none has reported the proportion of offspring with an individually identified boar (Alexandrowicz \& Ratajszczak, 1969; Benzenko, Terent'eva, Zhirnov, Chernushenko \& Jaffe, 1970; Roberts \& Carroll, 1939). The previous reports have not identified individual boars but only designated boars by breeds or as the first used or by their age. The proportion of litters containing offspring from both sires ranged from $58 \%$ to $79 \%$ in these previous studies. In the present study, there were 17 litters entirely from the first boar used, 10 from the second, and 24 with litters containing offspring from both boars. Of the total offspring very nearly half were from the first boar. These observations are similar to those made in other studies. In one study (Benzenko et al., 1970), three times as many piglets were sired by one boar than by the other boar in a heterospermic pairing. In the present experiment, the differences between boars were even greater in several pairs.

The results of our study are in agreement with those of Beatty et al. (1969) who found that bulls 
siring a preponderance of offspring after heterospermic insemination were also more fertile following homospermic insemination and they reasoned that small differences in fertility between bulls could be detected with greater certainty by heterospermic insemination because it was much more sensitive, at least 170 times, than homospermic insemination.

This greater sensitivity in detecting differences in fertility between males by heterospermic insemination in comparison to homospermic insemination is shown in the following example. When comparing Cock LO with the C cocks, LO clearly sired the preponderance of chicks $(87 \%, 96 \%$ and $98 \%$ ) (Table 1 ). $\mathrm{He}$ also sired $87 \%$ of the chicks when competing against Cock $\mathrm{C} 1$, whereas his two breed-mates, Cocks L 1 and L2, sired only $59 \%$ of chicks when competing against Cock C1. Cock L0 in turn fertilized as high a percentage of hens as other cocks, fertilized $80 \%$ of eggs as compared $64 \%$ or less for other cocks, and had an embryonic survival rate, $98 \%$ of the eggs fertilized, higher than that for other cocks. Boar Y1 followed essentially the same pattern as Cock L0 throughout the double-mating and the single-mating tests. If, on the other hand, one were seeking the least-fertile males to eliminate them from the breeding herd, the consistency in the pattern of Cocks C2 and C3 and Boars D8 and Y4 shows that they could be detected readily by heterospermic tests. Thus, it appears that the relationship between fertility ranking by heterospermic and homospermic methods is consistent from one species to another in chickens, pigs and cattle, and at both ends of the scale of fertility.

In the experiment using reduced numbers of spermatozoa/hen, although there was a direct relationship between sperm number and fertility for both males, efficiency and sensitivity were not increased and we do not know why. Even if this method were reasonably sensitive and efficient for estimating differences in relative male fertility, the low conception rates associated with the method would make it unacceptable for large field trials. In contrast, heterospermic inseminations are efficient and conception rates are normal. Highly fertile males and subfertile males are easily identified following heterospermic insemination or double mating. The hierarchy of males in a breeding herd would not be expected to fluctuate greatly because the proportion of offspring sired by 2 males is consistent over time (Beatty, 1960; Beatty et al., 1969; Martin et al., 1974; Beatty, Stewart, Spooner \& Hancock, 1976). Therefore, when a male of unknown fertility is introduced into the breeding herd, his rank among a group of males could easily be determined by heterospermic competition between any one of the ranked males and the male of unknown fertility. All males in a study could be tested against one standard animal to determine ranking. This simple method for identifying males of high fertility and low fertility enables the breeder to eliminate the male of low fertility from the breeding herd. This may be important in breeding herds and in artificial insemination centres because of the relatively low correlation between the usual measures of semen quality and subsequent fertility.

In the present experiment Boars Y1 and Y4 were litter mates, were housed, fed, and managed similarly, had equal libido, both appeared normal and healthy, and quality of semen did not differ between them by a superficial, gross examination and microscopic examination. Boar Y1 was clearly more fertile than Boar Y4 in the competitive mating test and also in the homospermic test. Homospermic estimates are of little consequence in selecting fertile boars for most swine breeding herds, because relatively few boars are used in sufficient homospermic matings and there are few herds with accurate records of conception rate or litter size. Double mating tests made it possible to distinguish quite readily between these two boars with relatively few matings and with simple records.

In the microscopic examination of semen from the cocks, the only noticeable distinction between cocks was a higher proportion of cytoplasmic droplets on the spermatozoa of Cock C3. By all measures of fertility, both heterospermic and homospermic, there were clear differences between cocks not readily distinguishable by examination of semen. With the development of means of identifying which spermatozoon fertilizes which egg (Pursel, Johnson \& Borkovec, 1975), an accurate, consistent and reliable measure of fertility can be made by examining about 40 embryos a few days after insemination. After observation of these 40 embryos from a few cows, sheep, or about 5 gilts induced to ovulate, the relative fertility of males could be determined with greater certainty in a few days than is now the case with hundreds of matings under a variety of conditions requiring the examination of 30-60-day non-returns to oestrus or analysis of records of birth of offspring requiring a period of at least the length of gestation from the time of insemination. 
From a practical point of view, breeders who are not interested in the relative ranking of males but are concerned about fertile matings, mixing semen from several males will increase the chances that at least one male will be of relatively high fertility. In addition to increasing the odds that a mating would involve a fertile male with consequent higher fertility there is the added advantage that a greater proportion of offspring would be sired by the more fertile male. If there is a heritable component to either high or low fertility, then fertility of succeeding generations should not be reduced and may even be increased (Beatty, 1975).

\section{References}

Alexandrowicz, A. \& Ratajszczak, M. (1969) Heterospermic fertilization of sows as a means for reducing environmental variation in progeny testings. Symp. Pol. Genet. Soc. 1968, 157-161. (Anim. Breed. Abstr. 40, 123, 1972.)

Allen, C.J. \& Champion, L.R. (1955) Competitive fertilization in the fowl. Poult. Sci. 34, 1332-1342.

BeatTy, R.A. (1960) Fertility of mixed semen from different rabbits. J. Reprod. Fert. 1, 52-60.

BeATTY, R.A. (1975) Genetics of animal spermatozoa. In Gamete Competition in Plants and Animals pp. 61-68. Ed. D. L. Mulcahy. North-Holland Publishing Co., Amsterdam.

Beatty, R.A., Bennett, G.A., Hill, J.G., Hancock, J.L. \& StewarT, D.L. (1969) An experiment with heterospermic insemination in cattle. J. Reprod. Fert. 19, 491-502.

Beatty, R.A., Stewart, D.L., Spooner, R.L. \& HANCOCK, R.L. (1976) Evaluation by the heterospermic insemination technique of the differential effect of freezing at $-196^{\circ} \mathrm{C}$ on fertility of individual bull semen, $J$. Reprod. Fert. 47, 377-379.

Benzenko, S.P., Terent'eva, A.S., Zhirnov, I.E., Chernushenko, V.K. \& JAFFe, K.M. (1970) Distribution of progeny resulting from insemination of sows with semen from two boars. Sb. navch. Rab. uses. nauchno-issled. Inst. Zhivet. No. 20, 82-84. (Anim. Breed. Abstr. 40, 128, 1972.)
Bishop, M.W.H. (1964) Paternal contribution to embryonic death. J. Reprod. Fert. 7, 383-396.

BoENDER, J. (1966) The development of AI in pigs in the Netherland and the storage of boar semen. Wld. Rev. Anim. Prod. Special issue, pp. 29-44.

FinN, C.A. (1964) Influence of the male on litter size in mice. J. Reprod. Fert. 7, 107-111.

MARTIN, P.A., REIMERs, T.J., Lodge, J.R. \& DzIUK, P.J. (1974) The effect of ratios and numbers of spermatozoa mixed from two males on proportion of offspring. J. Reprod. Fert. 39, 251-258.

O'Reilly, P.J., Graves, C.N. \& Dziux, P.J. (1972) Heterospermic insemination of rabbit semen as a means of evaluating techniques of semen handling. J. Reprod. Fert. 29, 49-56.

Pursel, V.G., Johnson, L.A. \& Borkovec, A.B. (1975) Effects of in-vitro treatment of boar spermatozoa with TEPA on the fertilization and development of pig eggs. J. Reprod. Fert. 45, 459-552.

Roserts, E. \& Carroll, W.E. (1939) A study of hybrid vigor in a cross between Poland China and Duroc Jersey swine. J. agric. Res. 59, 847-854.

Stewart, D.L., Spooner, R.L., BennetT, G.H., Beatty, R.A. \& HaNCOCK, J.L. (1974) A second experiment with heterospermic insemination in cattle. J. Reprod. Fert. 36, 107-116.

Received 6 September 1976 